\title{
MISOPROSTOL VERSUS OXYTOCIN FOR INDUCTION OF LABOUR AT TERM AND POST TERM PREGNANCY OF PRIMIGRAVIDA
}

\author{
Malati Tripathi, ${ }^{1}$ Ayushma Adhikari, ${ }^{1}$ Bibhushan Neupane ${ }^{2}$
}

\section{ABSTRACT}

\section{INTRODUCTION}

To compare effectiveness and safety of sublingually administered misoprostol and intravenously infused 10 units of oxytocin for labor induction at term and post term pregnant women in Gandaki Medical College Teaching Hospital (GMCTH).

\section{MATERIAL AND METHODS}

This is a prospective study conducted in Department of Obstetrics and Gynaecology in Gandaki Medical College and performed on 120 patients of primigravida with cephalic presentation at term and post-term pregnancy. Patients were given $50 \mu \mathrm{g}$ sublingual misoprostol 6 hourly (two doses) and 5 units of oxytocin in 500ml RL started from 10 drops up to 60 drops till effective contraction occur with maximum of 10 units oxytocin. Maternal and fetal outcomes were observed. Collected data were analyzed using SPSS and MS Excel.

\section{RESULTS}

There were no significant differences between the groups concerning time duration between inductions to delivery time, indications of caesarean section, different modes of delivery and for the Apgar score at one and five minutes.

\section{CONCLUSION}

Both oxytocin and misoprostol are effective and safe for induction of labour.

KEYWORDS Induction of labour, maternal outcome, misoprostol, neonatal outcome, oxytocin

1. Department of Obstetrics \& Gynaecology,Gandaki Medical College, Pokhara, Nepal

2. Department of Obstetrics \& Gynaecology, Nepalese Army Institute of Health Sciences, Kathmandu, Nepal DOI: https://doi.org/10.3126/jucms.v6i2.22497

\author{
For Correspondence \\ Dr. Malati Tripathi \\ Department of Obstetrics and Gynaecology \\ Gandaki Medical College \\ Pokhara,Nepal \\ Email:drmalatitripathigme@gmail.com
}




\section{INTRODUCTION}

Induction of labour is defined as initiation of labour by artificial means prior to the onset of spontaneous labour. ${ }^{1}$ It is widely practised to prevent adverse events such as caesarean section, prolonged labour, postpartum haemorrhage and traumatic birth to both mother and infants, if pregnancy is continued beyond term. ${ }^{2}$

Labour may be induced by pharmacological methods or mechanical methods. Among pharmacological methods, oxytocin and misoprostol are the most commonly used for induction of labour. The worldwide increase in use of these methods during recent years necessitates a careful research on indications, resulted risks, benefits, time duration betweeninductions to delivery and also maternal complications of labour induction especially related to oxytocin and misoprostol (a synthetic prostaglandinE $E_{1}$ ).

Therefore, this study was conducted to evaluate the effectiveness and the safety of sublingually administered misoprostol in comparison to that of intravenously infused 10 units of oxytocin for labour induction at term and post term pregnant women.

\section{MATERIAL AND METHODS}

This is a prospective study conducted in Department of Obstetrics and Gynaecology in Gandaki Medical College (GMC), Pokhara, Nepal over 2 years from $9^{\text {th }}$ January, 2017 to $8^{\text {th }}$ January, and 2018. The present study was cleared by the Ethical Committee of GMC. Informed verbal consent was taken from the patient. This study was performed on 120 patients of primigravida with cephalic presentation at term and post-term pregnancy. The population for this study are those women of age group 20-30 years in whom induction of labour was decided after admission in GMCTH, Pokhara for delivery.

The inclusion criteria in this study were alive singleton primigravida at gestational age 37 weeks or more with cephalic presentation with no contraindication of vaginal delivery. The exclusion criteria were multiple pregnancy, antepartum hemorrhage, pre-labour rupture of membrane, cardiac disease, diabetic pregnant mother and abnormal cephalic presentation.

Patients were randomly divided into two groups; 60 patients in each group. Group I: Patients who will receive $50 \mu \mathrm{g}$ sublingual misoprostol 6 hourly of two doses. Group II: Patients who will receive 5 units of oxytocin in $500 \mathrm{ml}$ RL started from 10 drops up to 60 drops till effective contractions occur with maximum of 10 units oxytocin. Study variables were as follows: indication of induction of labour (IOL), induction to delivery interval, mode of delivery, indication of lower segment caesarean section, neonatal outcome and maternal complication.

Before starting of induction by any methods, patients were asked to empty her bladder and bishop's scoring was done to check cervix status. $50 \mu \mathrm{g}$ misoprostol was given sublingually and repeated after 6 hours, if needed (maximum two doses only). 5 units in $500 \mathrm{ml}$ of RL infusion of oxytocin was started on whom induction had been decided. If effective contraction was not established and there was no foetal distress and abnormal uterine contraction, then, 10 units oxytocin in $500 \mathrm{ml}$ RL was started from 30 drops upto 60 drops, again, the rate was increased every 30 minute by 10 drops up to 60 drops. If effective uterine contractions occured at any rate, that rate was maintained upto delivery of baby. Active third stage management was done and oxytocin drip was continued one hour after delivery. Foetal heart sound (FHS) was monitored every 30 minutes during induction period of labour. Collected data were compiled and analysed using SPSS software in 21.0 version and MS-excel. The treatment groups were compared to evaluate maternal and fetal/neonatal outcomes.

\section{RESULTS}

For misoprostol group, post-dated pregnancy was found to be the major indication for IOL, that is, $26(43.3 \%)$ followed by term pregnancy, $20(33.3 \%)$. For oxytocin group, term pregnancy was found to be the major indication for IOL, that is, $23(38.3 \%)$ followed by post-date pregnancy $21(35 \%)$ (Table 1).

\section{Table 1. Indication of induction}

\begin{tabular}{|l|l|l|l|l|l|}
\hline \multirow{2}{*}{} & \multicolumn{3}{|c|}{ Misoprostol } & \multicolumn{3}{c|}{ Oxytocin } & \multirow{2}{*}{ p-value } \\
\cline { 2 - 5 } & No. & $\%$ & No. & $\%$ & \\
\hline Post- date pregnancy & 26 & 43.3 & 21 & 35 & 0.350 \\
\hline Gestational hypertension & 4 & 6.7 & 3 & 5 & 1 \\
\hline Intrauterine growth restriction & 1 & 1.7 & 1 & 1.7 & 1 \\
\hline Rh-negative mother & 1 & 1.7 & 1 & 1.7 & 1 \\
\hline Polyhydramnios & 1 & 1.7 & 1 & 1.7 & 1 \\
\hline H/O- subfertility & 2 & 3.3 & 3 & 5 & 1 \\
\hline Oligohydramnios & 2 & 3.3 & 3 & 5 & 1 \\
\hline- & 20 & 33.3 & 23 & 38.3 & 0.568 \\
\hline Other maternal indication & 2 & 3.3 & 2 & 3.3 & 1 \\
\hline Foetal indication & 1 & 1.7 & 2 & 3.3 & 1 \\
\hline
\end{tabular}

According to hour intervals from induction to delivery, it was seen that more number of patients delivered in $<10$ hours in oxytocin group than in misoprostol group whereas other 22 women in misoprostol and 18 women in oxytocin-group were delivered within 20 to 36 hours of induction. 26 women in misoprostol group and 23 women of oxytocin group delivered within 10-20 hours .There was statistically non-significant difference $(p>0.05)$ between two groups in all the time duration (Table 2). 
Table 2. Detail of time duration between-inductions to delivery

\begin{tabular}{|l|l|l|l|l|l|}
\hline \multirow{2}{*}{ Induction to delivery (hrs) } & \multicolumn{3}{|c|}{ Misoprostol } & \multicolumn{3}{r|}{ 0xytocin } & p-value \\
\cline { 2 - 6 } & No. & $\%$ & No. & $\%$ & \\
\hline$<10$ & 12 & 20 & 19 & 31.7 & 0.144 \\
\hline 10 to 20 & 26 & 43.3 & 23 & 38.3 & 0.577 \\
\hline 20 to 36 & 22 & 36.7 & 18 & 30 & 0.439 \\
\hline
\end{tabular}

After induction, out of 120 cases, the rate of normal delivery was maximum for both misoprostol group [43 (71.7\%)] and oxytocin group [41(68.3\%)]. The majority of the women provided with misoprostol $16(26.7 \%)$ and oxytocin 17 (28.3\%) underwent caesarean section whereas rate of vacuum delivery was minimum 1 (1.7\%) for misoprostol and 2 (3.3\%) for oxytocin group. There was statistically non-significant difference $(>0.05)$ between two groups in all modes of deliveries (Table 3).

Table 3. Mode of delivery

\begin{tabular}{|c|c|c|c|c|c|}
\hline & \multicolumn{2}{|c|}{ Misoprostol } & \multicolumn{2}{|c|}{ Oxytocin } & \multirow[t]{2}{*}{ p-value } \\
\hline & No & $\%$ & No & $\%$ & \\
\hline Normal delivery & 43 & 71.7 & 41 & 68.3 & 0.690 \\
\hline Caesarean section & 16 & 26.7 & 17 & 28.3 & 0.838 \\
\hline Vacuum delivery & 1 & 1.7 & 2 & 3.3 & 1 \\
\hline
\end{tabular}

Of the total 33 caesarean section cases, fetal distress was found to be the most common reason for caesarean in both groups [misoprostol 12(20\%) and oxytocin 11(18.3\%)] followed by failure of induction for misoprostol [2(3.3\%)] and oxytocin $[3(5 \%)]$.There was statistically non-significant difference $(\mathrm{p}>0.05)$ between two groups in all indications of caesarean section (Table 4$)$.

Table 4. Indication of LSCS (Lower segment caesarean section)

\begin{tabular}{|l|l|l|l|l|l|}
\hline \multirow{2}{*}{} & \multicolumn{3}{|c|}{ Misoprostol } & \multicolumn{3}{r|}{ Oxytocin } & p-value \\
\cline { 2 - 6 } & No. & $\%$ & No. & $\%$ & \\
\hline Fetal distress & 12 & 20 & 11 & 18.3 & 0.817 \\
\hline Failed induction of labour & 2 & 3.3 & 3 & 5 & 1 \\
\hline Non progress of labour & 1 & 1.7 & 2 & 3.3 & 1 \\
\hline Other indication & 1 & 1.7 & 1 & 1.7 & 1 \\
\hline
\end{tabular}

When Apgar score $<6$ at 1 min was analyzed, 8 (13.3\%) cases in the misoprostol and $10(16.7 \%)$ in the oxytocin groups were found and for Apgar score >6, 52 (86.7\%) cases in misoprostol and $50(83.3 \%)$ cases in oxytocin were found . Similarly, when Apgar score $<7$ was analyzed , $3(5 \%)$ cases in misoprostol and $5(8.3 \%)$ in the oxytocin group were found and for Apgar score $>7,57$ (95\%) cases in the misoprostol and $55(91.7 \%)$ in the oxytocin were found. No statistical significant difference $(\mathrm{p}>0.05)$ was found between two groups for the Apgar score i.e. $<6$ and $<7$ at one minute and five minutes (Table 5).
Table 5. Fetal outcome and Apgar score (In all type of deliveries)

\begin{tabular}{|c|c|c|c|c|c|c|}
\hline \multicolumn{2}{|c|}{ Apgar-score } & \multicolumn{2}{|c|}{ Misoprostol } & \multicolumn{2}{|c|}{ Oxytocin } & \multirow[t]{2}{*}{ p-value } \\
\hline \multirow{3}{*}{$\begin{array}{l}\text { Apgar-score } \\
\text { in one min. }\end{array}$} & & No. & $\%$ & No. & $\%$ & \\
\hline & $<6$ & 8 & 13.3 & 10 & 16.7 & \multirow[t]{2}{*}{0.609} \\
\hline &. & 52 & 86.7 & 50 & 83.3 & \\
\hline \multirow{2}{*}{$\begin{array}{l}\text { Apgar-score } \\
\text { in } 5 \mathrm{~min} \text {. }\end{array}$} & $<7$ & 3 & 5 & 5 & 8.3 & \multirow[t]{2}{*}{0.714} \\
\hline & $\geq 7$ & 57 & 95 & 55 & 91.7 & \\
\hline \multirow[t]{2}{*}{ Baby status } & $\begin{array}{l}\text { Baby admission in } \\
\text { NICU }\end{array}$ & 6 & 10 & 8 & 13.3 & \multirow[t]{2}{*}{0.570} \\
\hline & Baby with mother & 54 & 90 & 52 & 86.7 & \\
\hline
\end{tabular}

Table 6 shows the occurrence and distribution of maternal complications. Maternal complications were seen in total 29 sample size.

Table 6. Maternal complication

\begin{tabular}{|l|l|l|l|l|l|}
\hline \multirow{2}{*}{} & \multicolumn{2}{|c|}{ Misoprostol } & \multicolumn{2}{c|}{ Oxytocin } & p-value \\
\cline { 2 - 6 } & No. & $\%$ & No. & $\%$ & \\
\hline Nausea/vomiting & 9 & 15 & 3 & 5 & 0.068 \\
\hline Diarrhoea & 2 & 3.3 & 0 & & 0.496 \\
\hline Headache & 0 & & 1 & 1.7 & 1 \\
\hline Fever & 5 & 8.3 & 1 & 1.7 & 0.209 \\
\hline PPH & 5 & 8.3 & 3 & 5 & 0.714 \\
\hline No complication & 39 & 65 & 52 & 86.7 & 0.006 \\
\hline
\end{tabular}

Nausea and vomiting were most common side effects and more prevalent in the misoprostol group. There were $9(15 \%)$ cases in the misoprostol group versus $3(5 \%)$ cases in the oxytocin group presenting statistically non-significant difference $(\mathrm{p}>0.05)$. The incidence of diarrhea 2(3.3\%), fever $5(8.3 \%)$ and post-partumhemorrhage $5(8.3 \%)$ was seen more in miso-prostol-treated group. There was no significant difference $(>0.05)$ in complications of both the groups.

\section{DISCUSSION}

The aim of this study was to evaluate efficacy of sublingual misoprostol versus oxytocin drip for induction of labour in primigravida at term and post term in GMCTH. Health of mother and infant is affected, if pregnancy continues beyond term. IOL is indicated for various reasons regarding maternal and fetal conditions. The present study showed that post-term pregnancy was the most frequently encountered reason for induction of labour which is similar to the findings ofother studies. $^{3-8}$ Other indications found in our study were gestational hypertension, oligohydramnios, intrauterine growth restriction (IUGR), Rh-negative mother, polyhydramnios, history of sub-fertility, maternal indications and other fetal indications. Majority of the cases delivered within $24 \mathrm{~h}$ after intravenous oxytocin induction. The study showed that, although, the time intervals from induction delivery interval (IDI) were reduced in the oxytocin group compared with the misoprostol group $(<10 \mathrm{hrs})$ and the difference between both groups was not statistically significant $(p>0.05)$. The induction delivery interval in misoprostol group 
was similar to another study ${ }^{7}$ whereas this differs from other studies where shorter induction delivery interval was seen in misoprostol than oxytocin., ${ }^{9,10}$

There was no significant difference between the two groups in the mode of delivery as 43 women $(71.7 \%)$ delivered in the misoprostol group and 41 women $(68.3 \%)$ delivered in the oxytocin group. The incidence of cesarean section in the misoprostol group was $26.7 \%$ (16 cases) compared with $28.3 \%$ (17 cases) in the oxytocin group with non-significant difference $(p>0.05)$. These findings were in agreement with those of previous studies. ${ }^{11,12}$

The present study showed fetal distress to be most common reason for caesarean which is similar to previous study. ${ }^{6}$ Our study showed no significant differences between the groups for Apgar index at one and fifth minute of life. The majority of studies have shown similar findings of the present study. ${ }^{13,14}$ When perinatal result was evaluated by means of baby status i.e admission in NICU and baby with mother, no significant difference $(p>0.05)$ was found.

IOL is also associated with some side effects. This study indicates that both misoprostol and oxytocin were associated with several complications. Nausea and vomiting were most common side effects of both the groups but more common in the misoprostol group. There were $9(15 \%)$ cases in the misoprostol group versus $3(5 \%)$ cases in the oxytocin group presenting statistically significant difference. The incidence of diarrhea, fever and post-partum hemorrhage was seen more in misoprostol-treated group. The side effects found in this study are similar to another study conducted in Nepal. ${ }^{1}$ The incidence of cesarean deliveries is increasing in Nepal. One of the reason may be due to maternal and fetal complications because of use of misoprostol and oxytocin. Although the use of misoprostol and oxytocin during IOL is associated with some maternal and foetal adverse effects, this study showed that a 50mcg sublingual misoprostol and 10 units of oxytocin in $500 \mathrm{ml} \mathrm{RL}$ are safe and effective for inducing labour.

\section{CONCLUSION}

These observations have clearly established the fact that both sublingual misoprostol and oxytocin drip are effective for inducing labour. However, there is still a lot to learn about use of misoprostol and oxytocin in obstetrics.
2. Wing, DA. Induction of labor. In: Queenan, JT, Hobbins, JC Spong, CY (eds) Protocols for high-risk pregnancies. Hoboken, NJ: Wiley-Blackwell, 2010, pp. 140-147.

3. Kelly, AJ, Tan, B. Intravenous oxytocin alone for cervical ripening and induction of labour. Birth 2001; 28(4): 280-281.

4. Daniel-Spiegel E, Weiner Z, Ben-Shlomo I, et al. For how long should oxytocin be continued during induction of labour? BJOG 2004; 111(4): 331-334.

5. Heimstad R, Romundstad PR, Eik-Nes SH, et al. Outcomes of pregnancy beyond 37 weeks of gestation. Obstet Gynecol 2006; 108(3 Pt 1): 500-508.

6. Prager M, Eneroth-Grimfors E, Edlund M, et al. A randomised controlled trial of intravaginal dinoprostone, intravaginal misoprostol and transcervical balloon catheter for labour induction. BJOG 2008; 115(11): 1443-1450.

7. Goldberg AB, Wing DA. Induction of labor: the misoprostol controversy. J Midwifery Womens Health 2003; 48(4): 244-248.

8. Yawn BP, Wollan P, McKeon K, et al. Temporal changes in rates and reasons for medical induction of term labor, 19801996. Am J Obstet Gynecol 2001; 184(4): 611-619.

9. Kramer RL, Gilson GJ, Morrison DS, et al. A randomized trial of misoprostol and oxytocin for induction of labor: safety and efficacy. Obstet Gynecol 1997; 89(3): 387-391.

10. Hofmeyr G, Gülmezoglu A, Alfirevic Z. Misoprostol for induction of labour: a systematic review.BJOG 1999; 106(8): 798-803.

11. Ngai S, Chan Y, Lam S. Labor characteristics and uterine activity: misoprostol compared with oxytocin in women at term with prelabor rupture of the membranes. BJOG 2000; 107 :222227.

12. Mozurkewich E. Prelabor rupture of membranes at term: induction techniques. Clin Obstet Gynecol 2006; 49 :672-683.

13. Escudero F, Contreras H. A comparative trial of labor induction with misoprostol versus oxytocin. Int J Gynaecol Obstet1997;57 (2):139-43.

14. Kadanali S, Küçüközkan T, Zor N, Kumtepe Y. Comparison of labor induction with misoprostol vs. oxytocin/prostaglandin E2 in term pregnancy. Int J Gynaecol Obstet 1996;55(2):99-104.

\section{REFERENCES}

1. Acharya T, Devkota R, Bhattarai B, Acharya R. Outcome of misoprostol and oxytocin in induction of labour. SAGE open medicine. 2017 Mar 21;5:2050312117700809. 